\title{
The Dichotomous Markov Process with Nonparametric Test Application; a Decision Support Method in Long-term River Behavioural Analysis: The Zayandeh Rud River; a Case Study from Central Iran
}

\author{
Mehdi F. Harandi, ${ }^{1}$ Shantia Yarahmadian, ${ }^{2}$ Mohammad Sepehrifar ${ }^{2}$ and Pieter H.A.J.M. van Gelder ${ }^{1}$ \\ ${ }^{1}$ Department of Hydraulic Engineering, Delft University of Technology, The Netherlands \\ ${ }^{2}$ Departments of Mathematics and Statistics, Mississippi State University, USA
}

\begin{abstract}
We use the Dichotomous Markov Noise (DMN) model with constant transition rates to describe the dynamics of fluctuations in the water level as a stochastic process, which is imposed on river discharge changes. By applying this model, two different regimes are determined for the long-term behaviour of the river. Based on these regimes, we define two nonparametric classes of the overall increasing/decreasing nature of the water level in the longterm behaviour, which are separated by an exponential steady state regime. In this paper, we develop a nonparametric testing procedure to test exponentially (steady state regime) against an alternative overall decreasing level distribution. The proposed test predicts the long-term regime behaviour of the river. The mathematical tools introduced to handle the problem should be of general use and the testing procedure can be considered as a new mathematical tool in the study of water level dynamics. Under conditions of data austerity and as a case of study, we examine the stochastic characteristics of the Zayandeh Rud ${ }^{1}$ River (Isfahan, Iran) water level.
\end{abstract}

Index Terms-Zayandeh Rud River, DMN, Real-time River Management, Extreme events modeling, Nonparametric Test.

\section{Introduction}

Environmental management and in the current context, specifically rivers, need a set of decision support tools to overcome the inherent uncertainties that appear in the system. These uncertainties, which are the result of the spatial variability of the driving processes, lack of comprehensive knowledge (Pourbakhshian et al., 2011), and/or the structural uncertainties of the system (the hydrodynamic, ${ }^{2}$ morphodynamic, ${ }^{3}$ and ecodynamic ${ }^{4}$ elements), should be tackled by decision makers and be supported by different support tools and methods. These uncertainties direct the feature of the models, simulations, and estimations, which are misleading for the decision makers who are struggling with water allocation issues (Syme, 2013) links to the river discharge.

A real-time decision-making process entails the knowledge of prior and subsequent consequences of the decisions. In this regard, a full understanding of the various systems'

\footnotetext{
${ }^{1}$ Zāyandé-Rūd or Zāyanderūd, also spelled as Zayandeh-Rood or Zayanderood.

2 i.e. discharge, water depth/level, flow velocity, turbulence, and inundation frequency.

${ }^{3}$ i.e. erosion, transport, deposition and sorting of sediment, bed forms, channels, bars, and longitudinal profiles.

${ }^{4}$ i.e. physical habitats, effects of vegetation such as flow resistance, sediment trapping, and vegetation succession such as colonization, growth, death plant forms, and sorting patterns.
} 
components and incorporating their interactions into appropriate methods for structured practical procedures of decision-making are of crucial importance. Indeed, making decisions needs a Decision Support System (DSS) "to support decision making in complex problems by structuring the information and by analysis and evaluation of the effects of different alternatives" (Sprague and Carlson, 1982).

Real-time river management ( $\mathrm{Wu}$ et al., 2012) is essentially a multifaceted decision making process. In its nature, Real-time river management is connected with hydrologic alterations, which are affected by upstream artificial reservoirs and precipitation variability (Zhao et al., 2012). One of the important obligations of river decision-makers is to regulate water based on the amounts of water, which should be apportioned to the users, particularly in semi-arid areas such as Iran and in certain seasons. As such, the decisions related to manageable water in the river are fully dependent on this parameter, which in practice is measurable in term of water level in every cross section of the river downstream. Certainly, annual, biannual or even middle-run discharge cannot be a reliable basis for long-run decisions. Theoretically, the output of the decisions related to managing a certain amount of water during yearly timeframes can be depicted as periodic water level data, which show the increasing and decreasing water levels influenced by such decisions. In this context, the important question is to realize how these periodical releases affect the long-term river behaviour.

Stochastic and deterministic models for studying water level fluctuations are both possible options to be used in DSS. However, because of the intrinsic randomness of the problem in time and space, stochastic models are more appropriate for the particular case of lower level DSS. By employing a good stochastic model, it is possible to predict the long-term behaviour of the river to a certain extent and also to use the data and statistics for the practical aspect of the problem. It should be added that the stochastic models also have some inevitable complexities and uncertainties, which cause tremendous difficulties for water governors as decision makers.

There have been numerous deterministic and stochastic modeling approaches for water level fluctuations. We would refer the reader to the adaptive network-based fuzzy inference system (Ying and Pan, 2008), the fuzzy Multi criteria (Zhang et al., 2009) 
Bayesian (Reggiani and Weerts, 2008) approach to decision-making, Markov Models (Kehagias, 2004; Vanem, 2011), artificial intelligence (Kisi et al., 2012), and the ANN and ANFIS models (Talebizadeh and Moridnejad, 2011; Magny et al., 2011). One of the main difficulties in using these models and their respective software is rooted in the morpho-dynamic upstream and downstream changes of rivers, which requires a continuous calibration of the software used in these methods. In general, the main challenges in river' DSS are related to the fact that the lack of sufficient data complicates projection of long-term trends for long-term plans for rivers. "While working on prediction of drought and flood years we are always making judgments and decisions on the basis of incomplete information, but this is preferable to decisions based on no information at all (Panda et al., 1996).

According to (Syme 2013), the scientists' common approach of overcoming uncertainty is by reducing "the information deficit to ensure certainty" to deal with water allocation decision-making issues. Therefore, access to long-term data on streams' steadiness, is in massive demand by decision makers. These data are important for both decisions made for semi-arid area, and also for development of other fundamental features. This paper aims to introduce a decision-maker-friendly method to deal with complexities and uncertainties stemming from the nature of this problem as well as from common differential equation models (Vanem, 2011), which are far from fulfilling decision makers' needs and contributing in the decisions that should be made under intensive extreme environmental events, such as drought (Unami et al., 2010) and floods. The paper discusses uses nonequilibrium systems driven by Dichotomous Markov Noise (DMN) model, which appears in a wide variety of phenomena in environmental sciences, physics and biology (Ridolfi et al., 2011; Yarahmadian et al., 2011). The result shows that DMN as a novel stochastic approach can link the hydrological data and long-term decision making uncertainties to highlight the sensitivity of the rivers and ecosystems as a whole, to such decisions.

In this regard, all of the involved uncertainties are captured as random increasing/decreasing discharges of the water level modelled by DMN as a consequence of the associated decision. Therefore, the DMN model as a DSS acts as a support tool to predict and estimate the overall nature of the increasing/decreasing river discharges, 
based on the long-term hydrometric data. River's discharge is directly calculated by water level, velocity and cross-section area-related relations. Water level is an important indicator of river decisions and of course is related to various interactions among the different components of the environmental-related systems that rely upon the organizational procedures involved in the management, and water resources of the river. The simplicity of this method is in providing a framework for the classification of the long-term behavioural of the river water level into the Overall Increasing Level (OIL) or Overall Decreasing Level (ODL) regimes (Zhao et al., 2012), which are differentiated by an exponential steady-state.

Afterwards, we use this classification to introduce a new nonparametric approach for the prediction through hypothesis applications applied to the real data. In this regard, it is important to mention that the parametric testing procedures for studying the monotonic trend in seasonal hydrologic time series are commonly confounded by problems such as non-normal data, missing values, seasonality, and serial dependence. On the other hand, appropriate nonparametric or distribution free statistical techniques are useful tools when data do not satisfy the conditions required by parametric statistical tests, and may be applied to a variety of hydrogeological problems.

The organization of the rest of the paper is as follows. The mathematical framework is introduced in Section 2. In Section 3, we discuss the application of the proposed methodology through examining the scale-discharge long-term data for the Zayandeh Rud River - in the central region of Iran - as a critical case study. After analysis of the

stochastic characteristics, a nonparametric approach applying the moment inequality method is introduced and the statistical testing results are provided. In Section 4 conclusion and the summary are presented.

\section{Mathematical Framework}

In this section we introduce Dichotomous Markov Noise for the modelling process.

\section{Dichotomous Markov Noise}

The dynamics of most environmental phenomena are stimulated by random behaviour. These behaviours are pervasive in nature. The underlying randomness, which is 
expressed as noise in the environmental dynamics, is the main cause of this variability. $L(t)$ is a continuous positive random variable, which represents the water level of the river under study in time. It is assumed that the rate of change of the water level randomly switches between constant positive and negative values $\left(v_{ \pm}\right)$measured from the zero scale (See Figure 1).

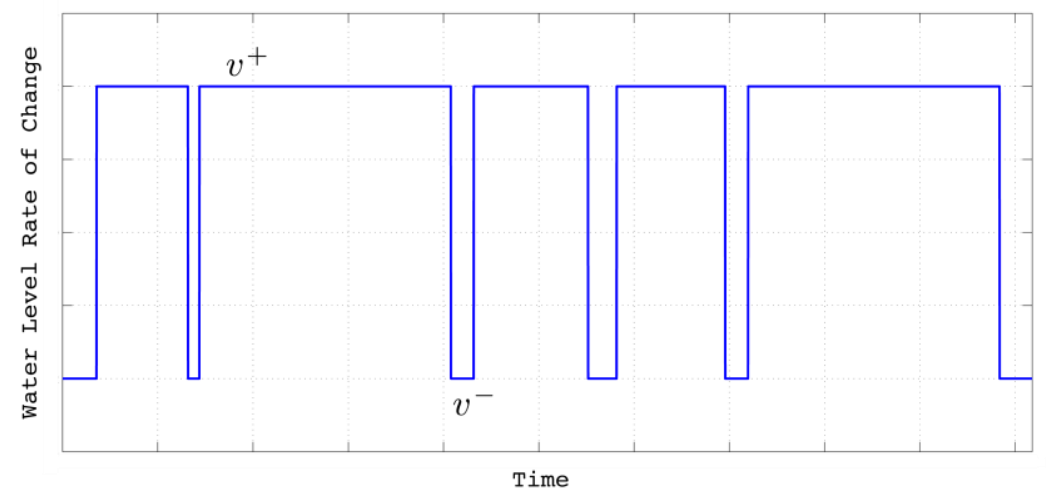

Figure 1: The Zayandeh Rud water level rate of change

Dichotomous Markov Noise (DMN) is defined as a two-valued stochastic process with the state space values $\pm v_{ \pm}$with constant transition frequencies of $\lambda_{ \pm}$, for the increase $(+)$ and decrease rate $(-)$ with the appropriate probabilities $\mathrm{p}_{ \pm}(\mathrm{t}),($ See Fig 1$)$. The switches of $v(\mathrm{t})$ are the Poisson process. The DMN is a coloured noise, i.e., a noise that has a non-negligible correlation time.

The evolution of $\mathrm{p}_{ \pm}(\mathrm{t})$, follows the following system of differential equations:

$$
\frac{d}{d t}\left(\begin{array}{l}
\mathrm{p}_{+}(\mathrm{t}) \\
\mathrm{p}_{-}(\mathrm{t})
\end{array}\right)=\left(\begin{array}{cc}
-\lambda_{+} & \lambda_{-} \\
\lambda_{+} & -\lambda_{-}
\end{array}\right)\left(\begin{array}{l}
\mathrm{p}_{+}(\mathrm{t}) \\
\mathrm{p}_{-}(\mathrm{t})
\end{array}\right)
$$

By using the initial values $p_{+}(0)=1$ and $p_{-}(0)=0$, the solutions are written as follows:

$$
\begin{aligned}
& p_{+}(t)=\frac{\lambda_{-}}{\lambda_{-}+\lambda_{+}}+\left(1-\frac{\lambda_{-}}{\lambda_{-}+\lambda_{+}}\right) e^{-\left(\lambda_{-}+\lambda_{+}\right) t} \\
& p_{-}(t)=\frac{\lambda_{+}}{\lambda_{-}+\lambda_{+}}\left(1-e^{-\left(\lambda_{-}+\lambda_{+}\right) t}\right)
\end{aligned}
$$


Stating the average rate (expected value of $v(t)$ ) as $\bar{v}(t)=v_{+} p_{+}(t)-v_{-} p_{-}(t)$, the average rate and the equilibrium point can be calculated as:

$$
\begin{aligned}
& \bar{v}(t)=\frac{v_{+} \lambda_{-}-v_{-} \lambda_{+}}{\lambda_{-}+\lambda_{+}}\left(1-e^{-\left(\lambda_{-}+\lambda_{+}\right) t}\right)+v_{+} e^{-\left(\lambda_{-}+\lambda_{+}\right) t} \\
& V=\lim _{t \rightarrow \infty} \bar{v}(t)=\frac{v_{+} \lambda_{-}-v_{-} \lambda_{+}}{\lambda_{-}+\lambda_{+}}
\end{aligned}
$$

Remark 1.1. The equilibrium point of the system is characterized by $\mathrm{V}$, which classifies the water level in three different regimes. Figure 2 shows that, when $\mathrm{V}>0$, water level increasing events are more frequent and the water level is in an Overall Increasing Level (OIL) class, whereas for $\mathrm{V}<0$ the decreasing events are more frequent and the water level is in an Overall Decreasing Level (ODL) class. ODL class is interpreted as a balance between the level increasing and decreasing events, which produce a steady-state mean water level.

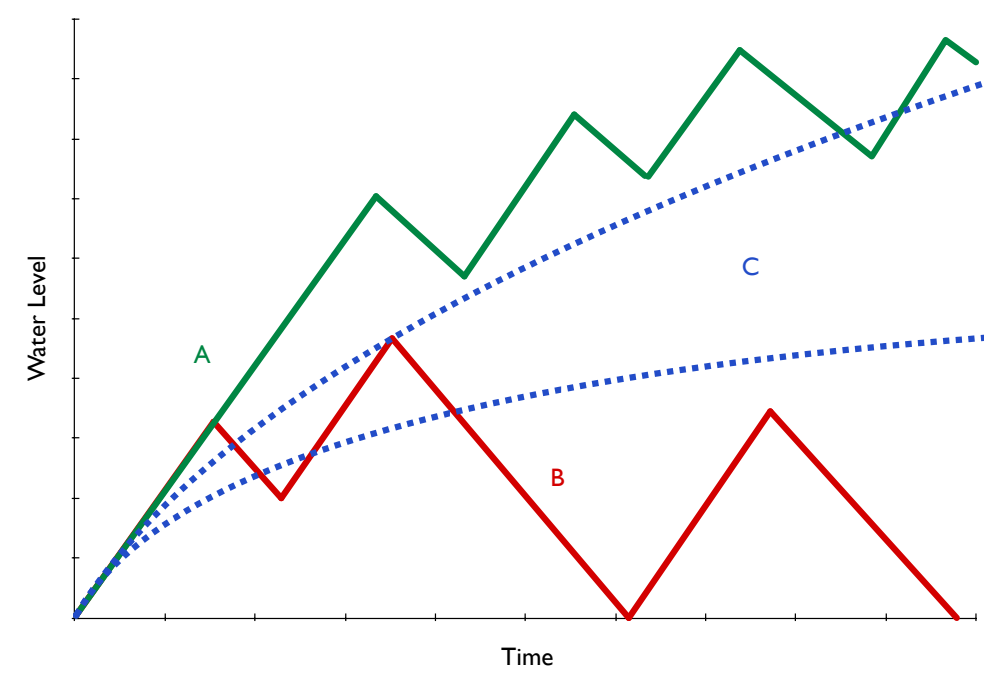

Figure 2: ODL and OIL regimes

Schematic plots of the water level (solid green and red lines) for the OIL (A) and ODL (B) regimes. Average water level (dashed blue lines) increases in the case of the OIL regime and reaches a steady-state value in the case of the ODL regime.

Now, consider the probability $P_{ \pm}(\mathrm{L}, \mathrm{t})$, the probability density function of the increasing 
(decreasing) water level in the interval $[\mathrm{L}, \mathrm{L}+\delta \mathrm{L}]$. The following lemma explains the derivation of the steady-state probability density function.

Lemma 1.1 In steady state, the probability distribution function (pdf) and the mean of water level are obtained through an exponential distribution $P(L)=\frac{1}{\Lambda} e^{-\frac{L}{\Lambda}}$ and $\Lambda=$ $\frac{v_{+} v_{-}}{v_{-} \lambda_{+}-v_{+} \lambda_{-}}$respectively.

Proof. The time evolution of probability distribution function $P_{ \pm}(L, t)$ is according to the differential equations (see Ridolfi et al., 2011, page 18-19 for the derivation of these equations):

$$
\frac{d}{d t}\left(\begin{array}{c}
P_{+}(L, t) \\
P_{-}(L, t)
\end{array}\right)=\left(\begin{array}{cc}
-v_{+} \frac{\partial}{\partial L}-\lambda_{+} & \lambda_{-} \\
\lambda_{+} & v_{-} \frac{\partial}{\partial L}-\lambda_{-}
\end{array}\right)\left(\begin{array}{l}
P_{+}(L, t) \\
P_{-}(L, t)
\end{array}\right)
$$

Setting the time derivative equal to zero, (1.6) reduces to

$$
\frac{\partial^{2} P_{ \pm}}{\partial L^{2}}+\frac{1}{\Lambda} \frac{\partial P_{ \pm}}{\partial L}=0
$$

This equation together with $\int_{0}^{\infty}\left[P_{+}(L)+P_{-}(L)\right] d L=1$ will establish the result.

\section{Application of the Proposed Methodology}

\section{Analysis of Stochastic Characteristics}

The traditional water-related question is about the pattern: is there any pronounced pattern in the river water level? Studying the past trends in stream flow enables us to develop strategies for the better utilization of water resources in the future. There is a huge amount of literature on the development of useful balance models in Real-time River Management. We refer the reader to the work of Conway, 1997, 2000; Kebede and Travi, 2006; Abdul Aziz and Burn, 2006; Burn and Elnur, 2002; and Burn et al., 2004.

\section{Case Study}

Zayandeh Rud is the most important river in the central part of Iran in Isfahan Province (See Figure 3). Situated on the Central Plateau of the country, it flows from west to east 
for 200 miles (for the basin's other characteristics see Table 1) and it has been the lifeline for civilization in this region.

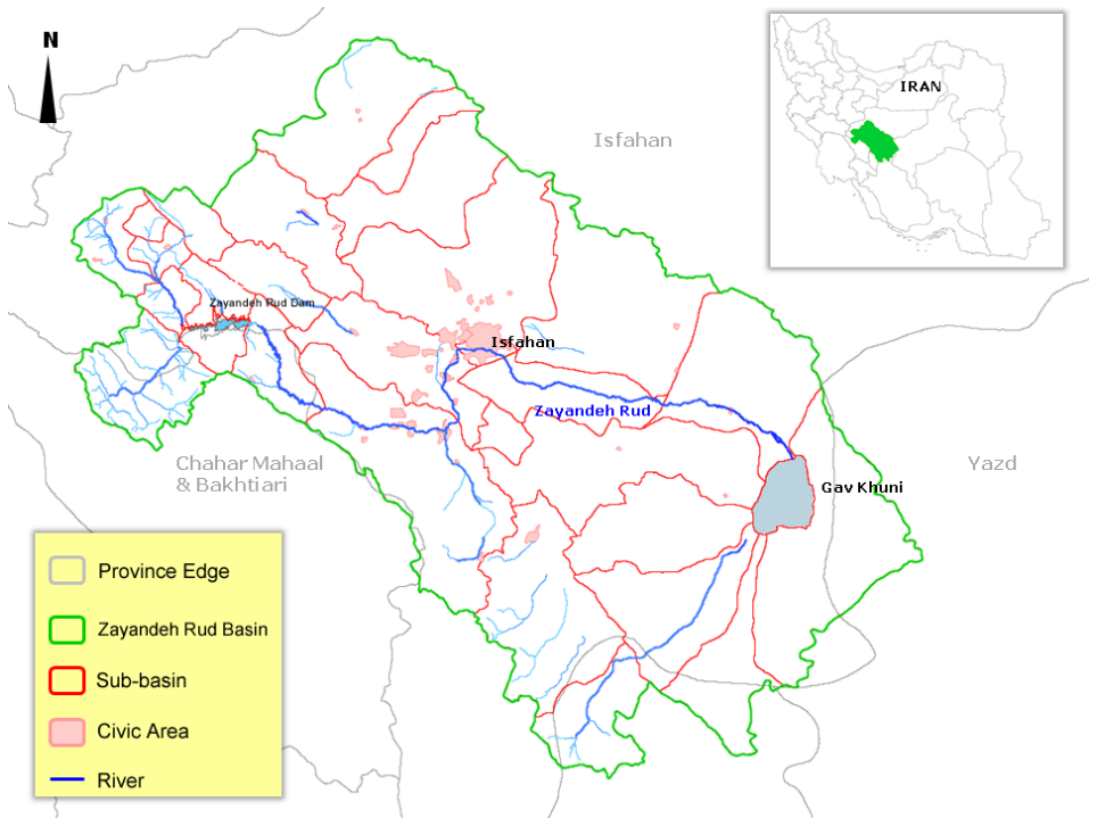

Figure 3: The Zayandeh Rud basin (retrieved from http://www.iwrm-isfahan.com)

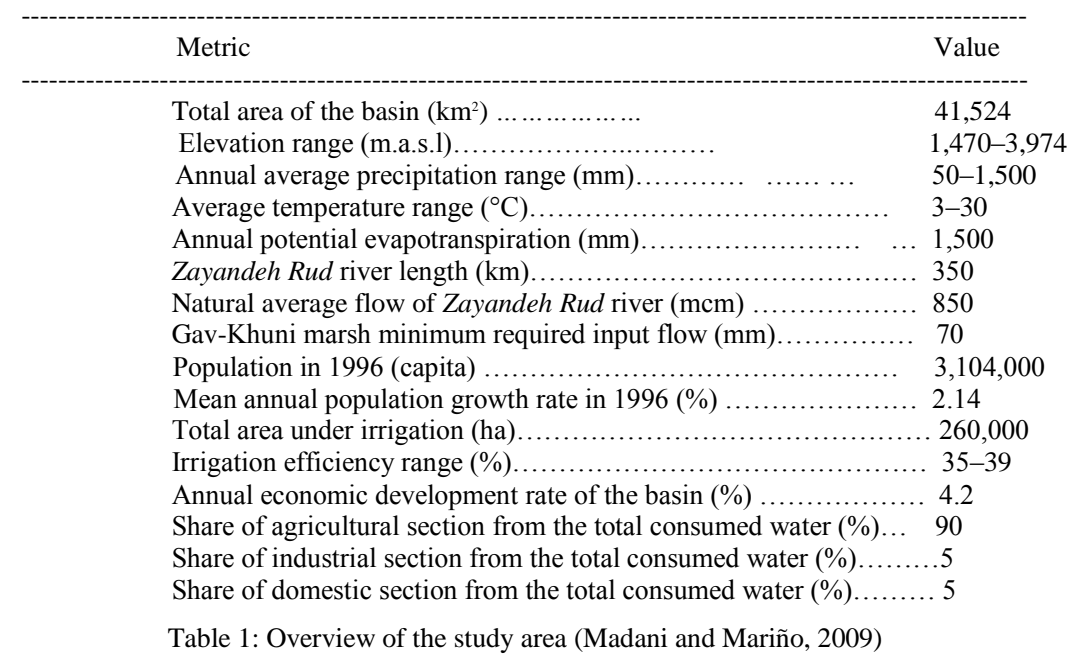

"Zayandeh Rud" is a Persian name, which means "Procreator River". Originating from the Zardkuh Mountain, it irrigates many gardens and farms. Zayandeh Rud is considered as the main source of verdure and fertility in Isfahan city and the region. Since 2000, the farmers and riparian city dwellers of the Zayandeh Rud River have been facing continual and drastic water shortages, while they had been expecting new water resources. Molle and Mamanpoush (2012) believe that fuzzy decision makings caused a lot of problems 
for the river such as "basin over building" and "socio-ecological breakdown". The Zayandeh Rud has been influenced by diverse and sophisticated decisions of decision makers, e.g. fiat allocation of water (Molle and Mamanpoush, 2012). As such, having a comprehensive view needs methods that can decrease the complexities of the river's long-term circumstances (Molle et al., 2008).

\section{Zayandeh Rud}

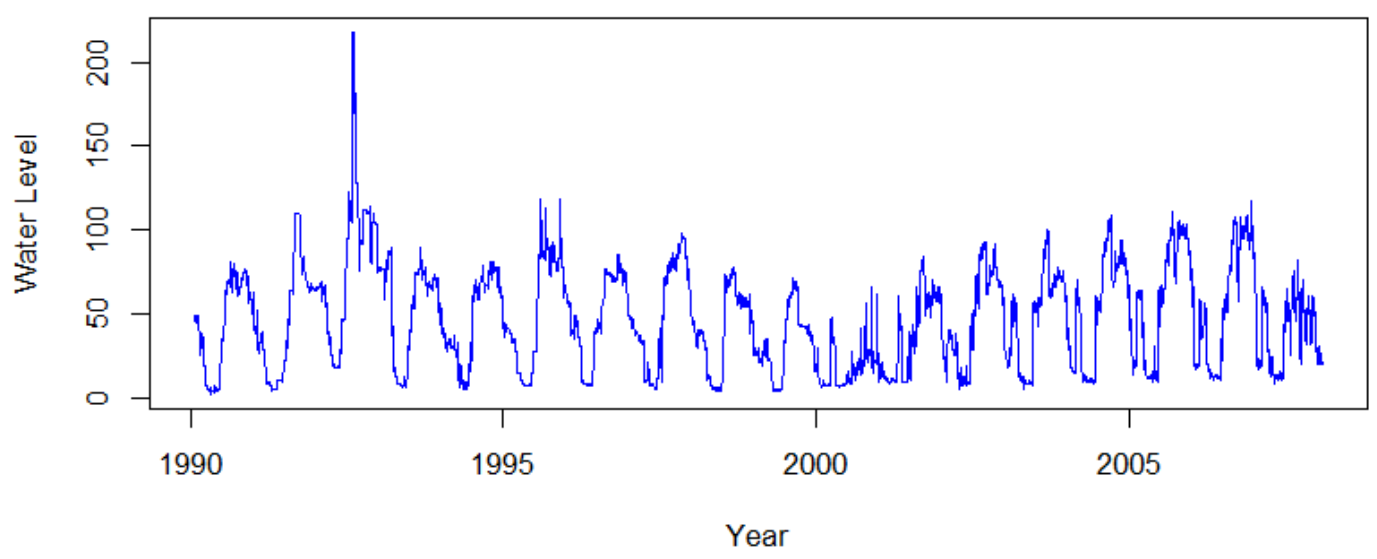

Zayandeh Rud

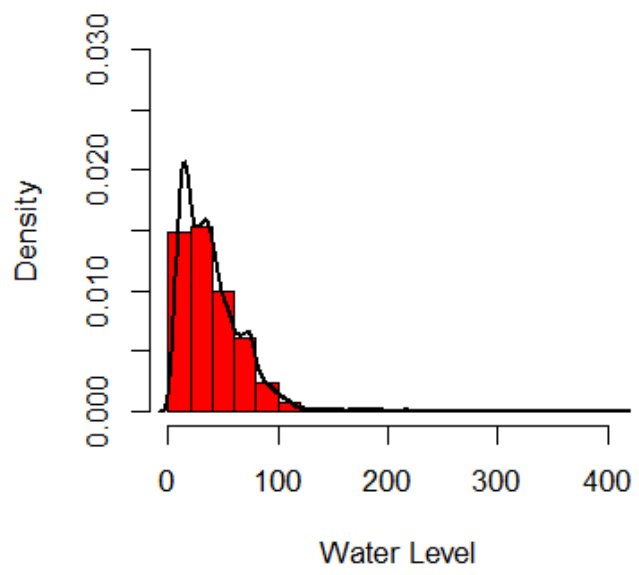

Normal Q-Q Plot

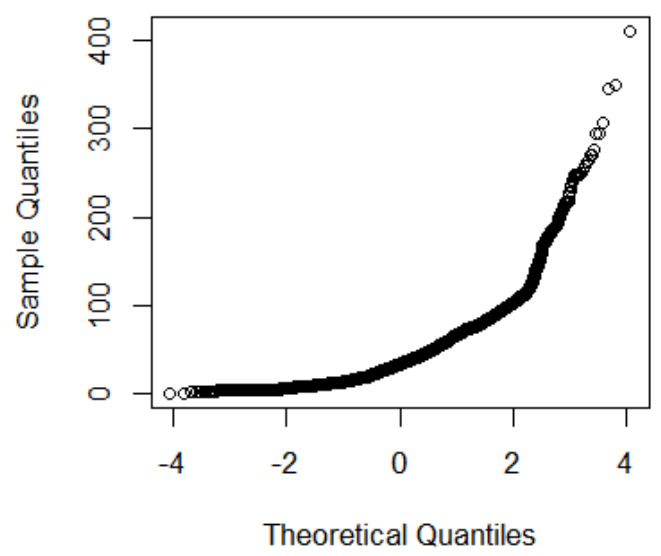

Figure 4: The Zayandeh Rud water level series 


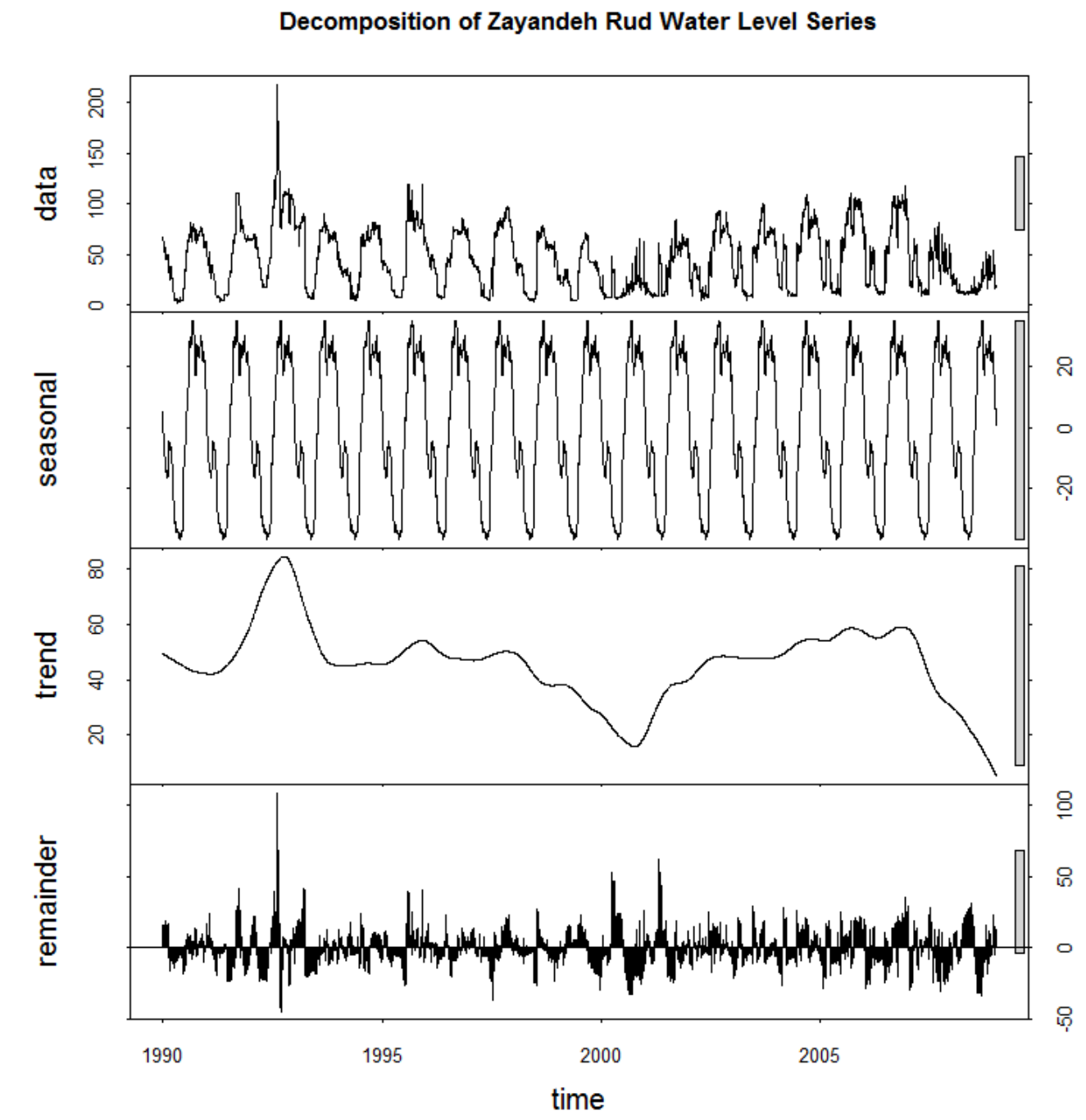

Figure 5: Additive decomposition of the Zayandeh Rud river data

In the additive model, the observed time series is considered to be the sum of three independent components: the seasonal, the trend and the remainder.

Observed series $=$ Trend + Seasonal + Remainder

The trend component reflects the long-term progression of the series (secular variation); the seasonal component reflects seasonality (seasonal variation) and the remainder component (or "noise") describes random, irregular influences and represents the residuals of the time series after the other components have been removed.

\section{A Nonparametric Approach: Moment Inequality}

The Zayandeh Rud water levels during 1990- 2008 are shown in Figure 2A. The diagram presents the stochastic dynamics of the water level over the years.

Remark 2.1. We have assumed that the Zayandeh Rud water level follows the assumptions of the DMN process, i.e., the water level rate of change is stochastically 
switching between two constant levels. This can be partially justified by the fact that the dam as a regulator often imposes constant changes on the river discharge.

Different tests for the normality of the water level series (Table 2) along with the Q-Q plot (Figure 4) reject the null hypothesis that the water level series has a normal distribution. In order to test the stationarity of the series on both level and trend, we have implemented the nonparametric Phillips-Perron test. This test computes the p-value as equal to 0.01 . At $5 \%$ significance level, we reject that the water level series has a unit root in favour of the stationary alternative.

Table 2: Test for normality of the Zayandeh Rud water level series

(Notation ** indicates that the test is significant at the level of $1 \%$.)

\begin{tabular}{|c|c|}
\hline Test for normality & p-Value \\
\hline Jarque-Bera & $<2.2 \mathrm{e}-16 * *$ \\
\hline D'Agostino & $<2.2 \mathrm{e}-16 * *$ \\
\hline One-sample Kolmogorov-Smirnov & $<2.2 \mathrm{e}-16 * *$ \\
\hline
\end{tabular}

DMN classifies the water level into two different regimes of ODL and OIL, which are separated by an exponential steady state (see Remark 1.1). In the following section, we provide the probabilistic characteristics of ODL and OIL classes of water level distribution.

\section{Moment Inequality Approach}

Let $L_{1}, L_{2}, \ldots, L_{n}$ be a sequence of independent identically distributed random water levels with survival function $\bar{F}=1-F$ and finite mean $\Lambda$ (See Lemma 1.1). Applying Lemma 1.2 shows that in steady state $(V=0)$, the boundary member for the aforementioned classes, ODL or OIL, is an exponential distribution.

Theorem 2.1. If water level distribution $F$ belongs to the $O D L$ class, then for all integers $r \geq 0$

$E\left\{\frac{1}{2(r+1)} L_{1}^{r+1} L_{2}^{2}-\frac{1}{r+2} L_{1}^{r+2} L_{2}+\frac{1}{2(r+3)} L_{1}^{r+3}\right\} \leq \Lambda E\left\{\frac{1}{r+1} L_{1} M_{1,2}^{r+1}-\frac{1}{r+2} M_{1,2}^{r+2}\right\}$ 
where $L_{1}, L_{2}$ are two stochastically independent copies of water level $L$ and $M_{1,2}=$ $\min \left(L_{1}, L_{2}\right)$, and $E\{L\}=\int_{0}^{+\infty} l d F$ which is the expected value of random water level $L$.

Corollary 2.1. Setting $r=0$ in (2.1):

$$
E\left\{\frac{1}{2} L_{1} L_{2}^{2}-\frac{1}{2} L_{1}^{2} L_{2}+\frac{1}{6} L_{1}^{3}\right\} \leq \Lambda E\left\{L_{1} M_{1,2}-\frac{1}{2} M_{1,2}^{2}\right\}
$$

The goal in the next section is to test if overall the water level falls in the ODL class.

Remark 2.2. The reader can find the proof for the theorem and corollary (2.1) in (Sepehrifar et al., 2012).

\section{Statistical Testing}

We define the following measure of departure from the null hypothesis to test the null hypothesis that the water level in the long-term falls into the steady state $\left(H_{0}\right)$ against any other alternatives in the ODL class (Sepehrifar et al., 2012):

$$
\delta=E\left\{\frac{1}{2} L_{1} L_{2}^{2}-\frac{1}{2} L_{1}^{2} L_{2}+\frac{1}{6} L_{1}^{3}-\Lambda\left(L_{1} M_{1,2}-\frac{1}{2} M_{1,2}^{2}\right)\right\}
$$

Note that the test statistic $\Delta=\frac{\delta}{\Lambda^{3}}$ has the scale invariate property with value $\Delta=0$ under the null, and $\Delta<0$ under the alternative. Now, let $L_{1}, L_{2}, \ldots, L_{n}$ denote random samples of $F$. An estimated form of $\Delta$ is $\hat{\Delta}=\frac{\widehat{\delta}}{\bar{L}^{3}}$, where $\bar{L}=\frac{1}{n} \sum_{i=1}^{n} L_{i}$ and

$$
\hat{\delta}=\frac{2}{n(n-1)} \sum_{1 \leq i \leq j \leq n}\left\{\frac{1}{2} L_{i} L_{j}^{2}-\frac{1}{2} L_{i}^{2} L_{j}+\frac{1}{6} L_{i}^{3}-L_{i}^{2} M_{i, j}+\frac{1}{2} L_{i} M_{i, j}^{2}\right\}
$$

To perform this test, we calculate $\hat{\Delta}$ from data and reject $H_{0}$ in favour of an alternative if the normal variate value $z_{1-\alpha}$ exceeds $\hat{\sigma}_{0}^{-1} \sqrt{n} \hat{\Delta}$. In this calculation, one may find the value of variance through the following theorem (see Sepehrifar et al., 2012):

Theorem 2.2. As $n \rightarrow \infty, \sqrt{n}\left(\widehat{\Delta}-\Delta_{0}\right)$ has an asymptotically normal distribution with mean $O$ and variance 


$$
\begin{aligned}
\sigma^{2}=\frac{1}{\Lambda^{6}} \operatorname{Var} & \left\{\frac{1}{6} L_{1}^{3}+\frac{1}{6} \int_{0}^{\infty} l^{3} d F(l)-\frac{1}{2} L_{1}^{3} \bar{F}\left(L_{1}\right)\right. \\
& \left.+\frac{3}{2}\left[L_{1} \int_{0}^{L_{1}} l^{2} d F(l)+\int_{0}^{L_{1}} l^{3} d F(l)-L_{1}^{2} \int_{0}^{L_{1}} l d F(l)\right]\right\}
\end{aligned}
$$

under the null hypothesis $\hat{\sigma}_{0}=1.173$.

The test statistic for this data set is $\widehat{\Delta}=-1.320264$. At $\% 5$ significant level $(\alpha=$ $0.05), \hat{\sigma}_{0}^{-1} \sqrt{n} \hat{\Delta}=-29.436809 \ll-1.644854$. Thus, from this calculated value, we must reject the null hypothesis and we conclude that the Zayandeh Rud water level series has the ODL property. This result shows an overall decreasing change in future for the Zayadeh-Rud River, which requires a proper series of decision actions. Figure 5 (Trend) also shows the decline in water level trend for this specific data set.

\section{Summary and Conclusion}

Rivers' unpredictability during the course of time and space and the influence of different parameters complicate the study of their long-term behaviour. This study proposes a new analytical framework that monitors and predicts river water level decreasing (increasing) long-term behaviour with a statistical river life analysis. In particular, water level is viewed as a dichotomous process with constant transition rates. Then a nonparametric testing procedure was applied to test if the water level driven by the DMN falls in the decreasing level (ODL) class or not. It is our hope that this method and its application will open the way for the study of river management procedures.

\section{Acknowledgements}

The authors wish to thank the consulting engineering company Payandab Tavan in Iran for its invaluable funding support and particularly for the hydrometric data of the case study.

\section{References:}

Abdul Aziz, O., Burn, D., 2006, Trends and variability in the hydrological regime of the Mackenzie River Basin, Journal of Hydrology, 319, 282-294.

Burn, D.H., Elnur, M.A., 2002, Detection of Hydrologic Trend and Variability, Journal of Hydrology 255, 107-122. 
Burn, D.H., Cunderlik, J.M. , et al., 2004, Hydrological trends and variability in the Liard River basin, Hydrological Sciences Journal 49(1), 53-68.

Conway, D., 1997, A water balance model of the upper Blue Nile in Ethiopia, Hydrological Sciences, 42, 265-282.

Conway, D., 2000, The climate and hydrology of the Upper Blue Nile River, The Geographical Journal, 166, 49-62.

Kebede, S., Travi, Y., 2006, Water balance of Lake Tana and its sensitivity to fluctuations in rainfall, Blue Nile basin, Ethiopia, Journal of Hydrology, 316, 133 247.

Kehagias, A., 2004, A hidden Markov model segmentation procedure for hydrological and environmental time series, Journal of Stochastic Environmental Research and Risk Assessment, 18, 2, 117-130, DOI 10.1007/s00477-003-0145-5.

Kisi, O., Shiri, J. and Nikoofar, B., 2012, Forecasting daily lake levels using artificial intelligence approaches, Computer \& Geoscience, 41, 169-180.

Madani, K., Mariño M.A., 2009, System Dynamics Analysis for Managing Iran's Zayandeh-Rud River Basin, Water Resource Management, 23, 2163-2187.

Magny, M. et al., 2011. Holocene hydrological changes in south-western Mediterranean as recorded by lake-level fluctuations at Lago Preola, a coastal lake in southern Sicily, Italy, Quaternary Science Reviews 30, 2459-2475.

Molle, F. and Mamanpoush, A., 2012, Scale, governance and the management of river basins: A case study from central Iran, Geoforum, 43, 2, 285-294.

Molle, F., Hoogesteger, J. and Mamanpoush, A., 2008, Macro- and Micro-Level Impacts of Droughts: The Case Of The Zayandeh Rood River Basin, Iran, Irrigation and Drainage, 57: 219-227.

Panda, S., Datta D. K. and Das, M. N. (1996), Prediction of drought and flood years in Eastern India using lengths of runs of annual rainfall, J. Soil \& Water Conserv., 40 (3 \& 4): $184-191$.

Pourbakhshian, S. et al., 2011, Morphological Stochastic Modeling of Braided Rivers' Scouring, Journal of Water and Soil (in Persian) 25, 2, 216-229.

Reggiani, P. and Weerts, A.H., 2008. A Bayesian approach to decision-making under uncertainty: An application to real-time forecasting in the river Rhine, Journal of Hydrology, 356, 56- 69.

Ridolfi Luca, D’Odorico Paolo and Laio Francesco, Noise-Induced Phenomena in the Environmental Sciences, Cambridge University Press, 2011.

Sepehrifar, M., Yarahmadian, S. and Yamada, R., 2012, On classes of life distributions: Dichotomous Markov Noise Shock Model With Hypothesis Testing Applications, http://arxiv.org/pdf/1210.0291.pdf.

Sprague R.H. and Carlson E.D., 1982. Building effective decision support systems, Volume 1, Prentice-Hall, Englewood Cliffs. 
Talebizadeh, M. and Moridnejad, A., 2011, Uncertainty analysis for the forecast of lake level fluctuations using ensembles of ANN and ANFIS models, Expert Systems with Applications 38, 4126-4135.

Syme, G., J., 2013. Acceptable risk and social values: struggling with uncertainty in Australian water allocation, Journal of Stochastic Environmental Research and Risk Assessment, 27, DOI 10.1007/s00477-013-0694-1.

Unami, K., Abagale, F., K., Yangyuoru, M., Badiul Alam, A., H., M., KranjacBerisavljevic, G., 2010, Stochastic differential equation model for assessing drought and flood risks, Journal of Stochastic Environmental Research and Risk Assessment, 24, 5, 725-733, DOI 10.1007/s00477-009-0359-2.

Vanem, E., 2011, Long-term time-dependent stochastic modelling of extreme waves, Journal of Stochastic Environmental Research and Risk Assessment, 25, 2, 185-209, DOI 10.1007/s00477-010-0431-y.

Wu, S., Lien, H., Chang, C. and Shen, J., 2012, Real-time correction of water stage forecast during rainstorm events using combination of forecast errors, Journal of Stochastic Environmental Research and Risk Assessment, 26, 4, 519-531, DOI 10.1007/s00477-011-0514-4.

Yarahmadian, S., Barker, B., Zumbrun, K. and Shaw, S. L., 2011, Existence and stability of steady States of a reaction convection diffusion equation modelling microtubule formation, Journal of Mathematical Biology, 63, 459-492.

Ying, L. and Pan, M., 2008, Using adaptive network based fuzzy inference system to forecast regional electricity loads, Energy Conversion and Management, 49, 205211.

Zhang, G., Ma, J., Lu, J., 2009. Emergency management evaluation by a fuzzy multicriteria group decision support system, Journal of Stochastic Environmental Research and Risk Assessment, 23, 4, 517-527, DOI 10.1007/s00477-008-0237-3.

Zhao, Q., Liu, S., Deng, L., Dong, S., Yang, J., Wang, C., 2012. The effects of dam construction and precipitation variability on hydrologic alteration in the Lancang River Basin of southwest China, Journal of Stochastic Environmental Research and Risk Assessment, 26, 7, 993-1011, DOI 10.1007/s00477-012-0583-z. 